\title{
SOLAR NOISE OBSERVATIONS FROM THE ALOUETTE SATELLITE
}

\author{
by T. R. HARTz
}

(Defence Research Telecommunications Establishment, Defence Research Board, Ottawa, Ontario, Canada)

RÉsumé. - On a pu observer des émissions solaires dans la gamme de fréquences 1,5 à $10 \mathrm{MHz}$ avec le récepteur à balayage de fréquence monté dans le satellite Alouette. Les sursauts de type III sont faciles à identifier contrairement à d'autres événements pour lesquels les enregistrements d'Alouette seuls sont insuffisants. A partir de la dérive en fréquence des sursauts de type III et d'un modèle de la couronne, on trouve que la vitesse de la source est de 0,1 à 0,15 c. A partir des durées des sursauts on donne une estimation provisoire des températures coronales.

On a observé aussi des événements de plus longue durée qui n'ont pu être classés et qui présentent une structure s'étendant jusqu'à la limite inférieure d'observation (1,5 M Hz). On les discute brièvement.

A вSTRACT. - Solar radio noise in the frequency range 1.5 to $10 \mathrm{MHz}$ appears sporadically in the Alouette sweepfrequency recordings above the galactic noise level. The type III bursts can be readily identified, but other spectral types are much more difficult to identify from only the satellite records. Using a plausible model for the coronal electron densities, the Type III frequency drift curves have been interpreted as corresponding to a source velocity in the range 0.1 to 0.15 times the velocity of light. Preliminary estimates have also been made of the coronal temperatures from some of the burst durations.

Other solar noise events of longer duration have not been classified other than as enhanced solar noise at this stage. These enhancements frequently show an intensity structure, extending down to the $1.5 \mathrm{MHz}$ lower frequency limit of the equipment. These events are discussed briefly.

l'езюме. - При посредстве приемника с частотной разверткой, установленного на спутниках Жаворонок (Alouette), можно было наблюдать солнечные эмиссии в диапазоне частот от 1,5 до 10 Мгц. Всплески типа III легко отождествимы, в противоположность другим событиям, для которых только регистрации Жаворонка, педостаточны. Исходя из частотного дрейфо всплесков типа III и модели короны, найдено, что скорость источника равна 0,1-0,15 с. Исходя из продолжительности всплесков, дана временнал оценка корональных температур.

Были также наблюдены собптия большей продолжителыности, которые не удалось. классифицировать и которые выявляют структуру простираюпгюся до нижнего предела наблюдения (1,5 Мгц). Они кратко обсуяддены.

\section{Introduction.}

The results on the galactic radio emissions obtained with the sweep-frequency receiver in the Alouette I satellite have been described elsewhere (HARTz 1964, 1965). That equipment, orbiting above the bulk of the ionosphere, sweeps in frequency from 0.5 to $12 \mathrm{MHz}$ and operates on the average for about 5 hours per day. Below the F-layer critical frequency and extending down to $1.5 \mathrm{MHz}$ (where a rapid reduction in the equipment sensitivity takes place), the receiver monitors the extra-terrestrial noise level, which in most cases is the galactic noise level. At times of solar activity, however, enhancements in this level often can be noted; such enhancements can be shown to be solar in origin, rather than terrestrial or ionospheric. In the 22 months since launch a substantial number of solar noise events have been recorded, and a preliminary assessment of some of these is given here.

Although it is expected that the solar noise in the 1.5 to $10 \mathrm{MHz}$ range would have characteristics similar to those found in the metric and decametric regions of the spectrum, difficulties have been encountered in classifying the noise events in the satellite recordings. These can be attributed in the main to restraints of the experimental situation, and include : (1) an amplitude nodulation related to the satellite spin rate appears in the records since the solar emissions come from essentially a point source, (2) the frequency range of the records is limited to about 2,5 octaves at best and often is much less than this because of a low F-layer critical frequency, (3) there is no 
data storage in the satellite and a particular recording only lasts for 10 minutes; except for the type III bursts the solar events are of much longer duration, (4) ionospheric refraction determines the effective antenna aperture and in many cases the lower end of the frequency range is lost because the solar source is excluded from the antenna pattern, and (5) the receiver sweeps through the frequency range once every 18 seconds, so that fine structure is not well portrayed in the records. As a consequence the type III bursts can be indentified readily in the recordings, but positive identification of other spectral types is more difficult. To be sure, reference can be made to spectral classifications from ground based observatories, but these data are not available at all times ; moreover, the distinguishing characteristics of the satellite data are not always as expected from the decametric classifications. Accordingly, the Alouette data are considered here in two categories only ; type III bursts, and other solar noise enhancements.

\section{Type III Bursts.}

The characteristics of the satellite records are shown in Figure $1 a$, for the normal galactic noise level, and in Figure 1 $b$, where solar noise appears above the galactic level. In each case ionospheric resonance spikes appear at the low frequency end (these serve to establish the parameters of the local environment), and ground transmissions contaminate the high-frequency end of the records. The recording shown in Figure $1 b$ was obtained part way through a type III burst ; the antennaaperture cut-off frequency is at $1.9 \mathrm{MHz}$ and the burst maximum is in the vicinity of $2 \mathrm{MHz}$. Records such as this have been scaled at spot frequencies throughout the burst event and the data have been portrayed in the form of threedimensional graphs as exemplified in Figure 2.

In this figure are shown three type III bursts that were observed in a ten minute interval : the ordinate and abscissa represent frequency and time respectively, and the burst intensity - relative to the galactic level - is indicated by the size of the circles. The gap at 1537 UT occurred when the satellite equipment shut off automatically and then was commanded on again almost immediately by the next telemetry station. In this particular case the interference level rose near the end of the record because of the decreasing critical frequency and the data near the end of the last bursts are uncertain. For this particular example the satellite spin axis was directed at the Sun so that no spin modulation appears in the data.

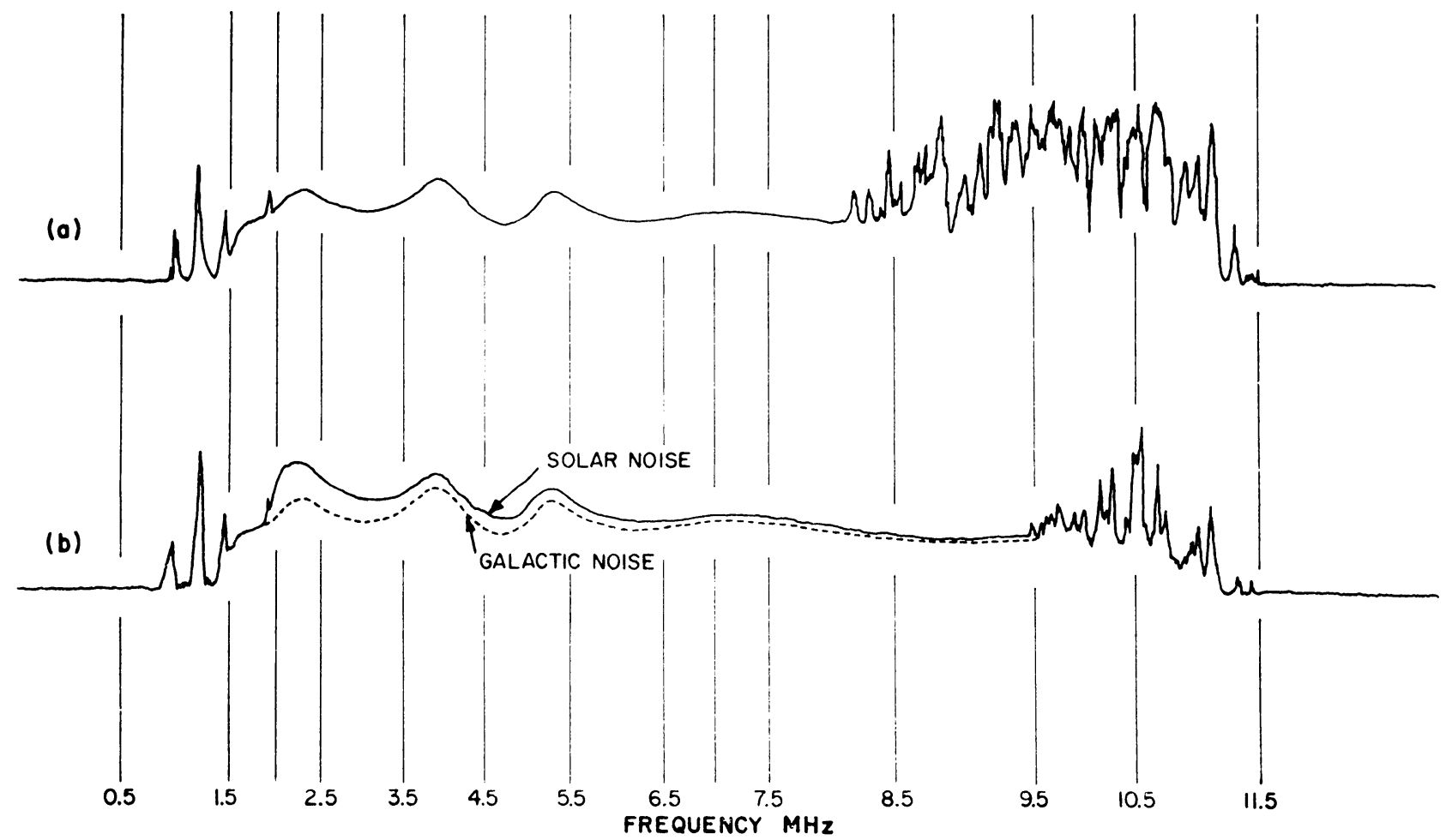

FIa. 1. - Alouette records showing $(a)$ the normal galactic radio noise level in the frequency range 1.5 to about $8 \mathrm{MHz}$, and $(b)$ solar noise above the galactic level from $1.9 \mathrm{MHz}$, the antenna aperture cut off, to about 9.5 MHz. 


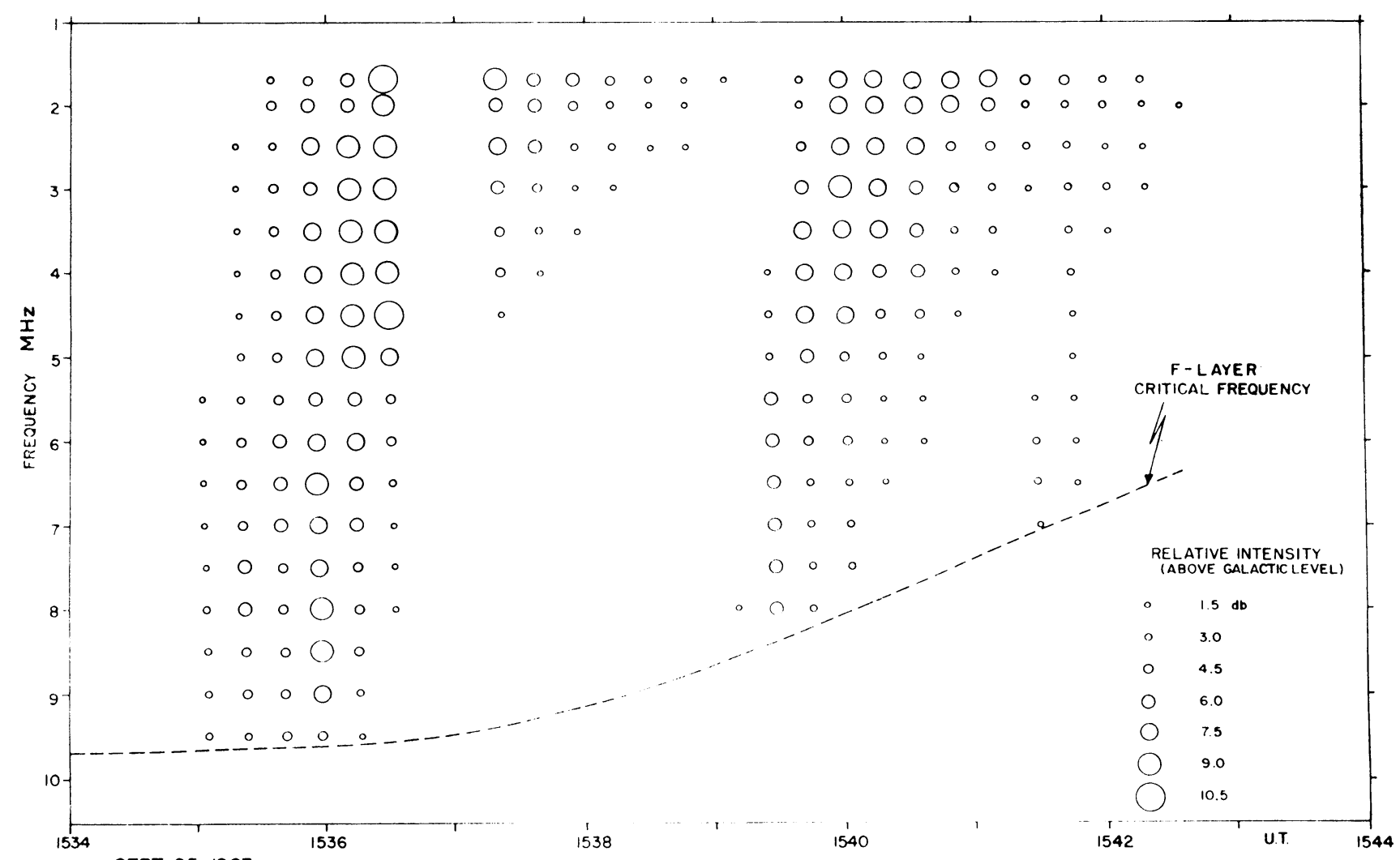

SEPT. 25, 1963

FIa. 2. - Spectra of three type III solar noise bursts. Although the satellite records are continuous in frequency, to produce this diagram scalings were made at $0.5 \mathrm{MHz}$ intervals, and the data are portrayed as various sized circles to represent the burst magnitude relative to the galactic noise level, as indicated.

From spectral plottings such as Figure 2 the rate of trequency drift for the maximum feature can be determined, and from this and a model for the electron number density in the corona it is possible to make estimates of the transport velocity of the noise source. Most workers who have followed this procedure with metric and decametric wavelength data have used an electron density distribution for the corona over active regions that exceeds the BAUMBACH-ALLEN model (ALLEN 1947) by about an order of magnitude. While there seems to be ample justification for this procedure out to distances of 2 or 3 solar radii (WILD et al. 1959, NeWKIRK 1959, ShaIN and Higgins 1959), the values at larger distances are much less certain. For radii between 3 and 10 the VAN DE HULST (1950) model seems preferable to the BAUMBACH-ALLEN model for the average corona, mainly because it agrees better with individual values at larger distances. Over active regions, then, it seems reasonable to choose an electron density model that exceeds that of BAUMBACH-ALLFN by a factor of about 10 at 2 or 3 solar radii, and which exceeds that of VAN DE HULST by about this same factor between 5 and 10 solar radii. Such an electron density distribution is shown in Figure 3 by the curve labelled H. For reference other electron density models as well as individual measurements in the corona and the interplanetary regions are also shown ( $A L$ LEN 1963). This particular choice for the radial distribution of electrons over active regions near the sunspot minimum epoch is somewhat arbitrary ; it does, however, lead to source velocities for type III bursts that are approximately constant over the range 4 to 10 solar radii, and this was not the case with several other plausible models that were tried.

To date some 20 type III bursts have been examined, and the velocities computed on the basis of this coronal model range between about $3 \times 10^{4}$ and $4.5 \times 10^{4} \mathrm{~km} / \mathrm{s}(0.1 c-0.15 \mathrm{c})$. Although this sampie is still too small to be representative of type III bursts in this frequency range, these results are lower than the lowest $(0.2 \mathrm{c})$ found from decametric observations. If further results support this conclusion, the adequacy of the chosen electron density model must 


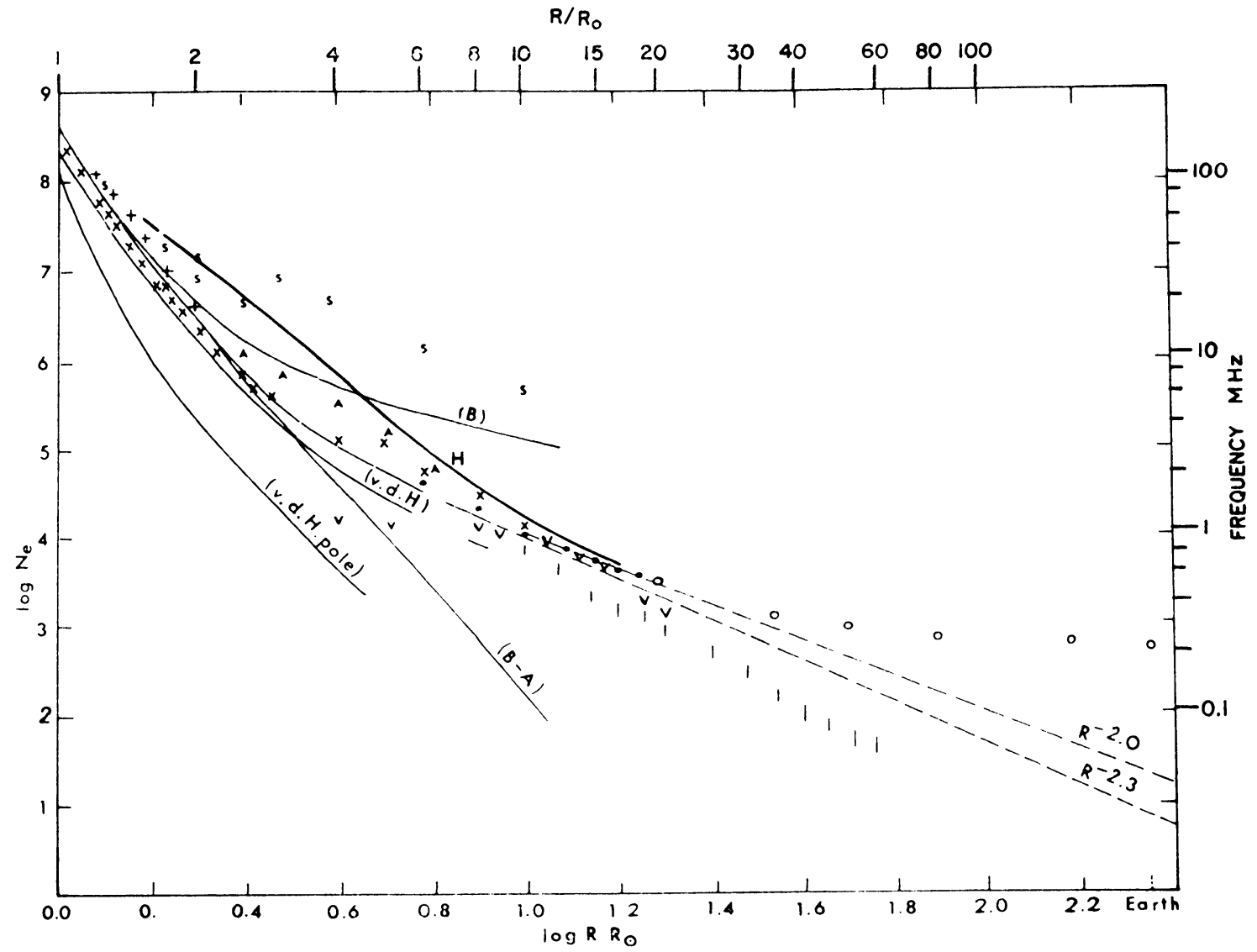

FI(x. 3. - Electron density and corresponding plasma frequency as a function of radial distance for the solar corona. $B$ is the Batumbach model, v. d. $\mathrm{H}$ is the van DE Hulst model, B-A is the Baumbach-Allen model, and $\mathrm{H}$ is the model chosen for the present purposes. The individual data points are identified by Allen (1963).

be questioned or else some deceleration process is to be sought for the emission source.

It has been suggested that the burst durations should be related to the kinetic temperature of the source region if particle collisions are primarily responsible for damping out the bursts (WeSTFOLD 1949, BоISCHOT et al. 1960). Durations have been obtained for some of the type III bursts examined, and here the duration is measured from the burst maximum to the $e^{-1}$ level. Because of such factors as the low frequency sweep rate on the Alouette receiver and the satellite spin, only approximate data are possible; these are listed for three frequencies in Table $I$. Also shown in Table I are the temperature computed using the relation (WARWICK 1964).

$$
\mathrm{T} \approx 6 \times 10^{-5} f^{4 / 3}(\Delta t)^{2 / 3},
$$

and the radial distances obtained from model $\mathrm{H}$ in Figure 3.

Objections have been raised to this procedure of estimating kinetic temperatures from the burst
TABLE I

\begin{tabular}{cccc}
$\begin{array}{c}\text { Frequency } \\
(\mathrm{MHz})\end{array}$ & $\begin{array}{c}\text { Duration } \\
-\end{array}$ & $\begin{array}{c}\text { Temperature } \\
-\end{array}$ & $\begin{array}{c}\text { Radial } \\
\text { Distance } \\
\left(\mathrm{R}_{0}\right)\end{array}$ \\
10 & 30 & - & - \\
5 & 50 & $0.7 \times 10^{8}$ & $\mathbf{3 . 8}$ \\
2 & 100 & $0.3 \times 10^{6}$ & 5.0 \\
\hline
\end{tabular}

durations (KUNDU 1964), but these appear to be less valid at these lower frequencies. The possibility that the bursts are contaminated by type $V$ noise cannot be entirely excluded, but there is no clear evidence for such contamination in the cases examined. Also if the dispersion of the exciting mechanism at the given plasma level is to mask the decay due to collisional damping, the times involved would seem to require an excessively large volume for the disturbance. 
In magnitude the type III bursts range from the galactic noise level to something like $16 \mathrm{db}$ above this level. The maximum flux, then, in the 1.5 to $10 \mathrm{MHz}$ frequency range is of the order of $10^{-18} \mathrm{Wm}^{-2} \mathrm{~Hz}^{-1}$.

\section{Other Solar Noise Enchancements.}

The Alouette recordings have been examined at times when ground based observatories have reported type II bursts, and in several cases portions of the bursts have been observed. Because the bursts durations exceed the recording interval, and because the records are spin modulated, little can be be said with certainty at present about the characteristics of the bursts at these low frequencies. Moreover, it would be exceedingly difficult to identify this burst type from only a ten minute satellite recording.

Events that are of relatively long duration and which are designated as continuum, type IV, and noise storms with type I bursts in decametric data, also cannot be classified easily in the satellite records. At such times the Alouette records show enhanced emissions with occasional intensity structure. During noise storms a rapidly changing structure can sometimes be seen, which at times is so regular as to suggest fast frequencydrift bursts. The changing antenna gain with frequency and the satellite spin modulation introduce interpretation difficulties, however, particularly if, as appears to be the more general case, the type I bursts are narrow band events. An example of this type of noise is shown in Figure 4.

In one case an abrupt intensity increase was observed in what might be described as continuum noise. (No decametric data are available until some three hours later when continuum noise is reported to be in progress.) Figure 5 shows the Alouette data at this time; the leading edge of the abrupt increase sweeps from high to low frequency in a time less than the $18 \mathrm{~s}$ between successive frames : if allowances are made for the effects of spin modulation on the record, the increase must be virtually simultaneous at all frequencies.

In general the intensities of the solar noise enhancements, including the type III bursts, at frequencies of 1.5 to $10 \mathrm{MHz}$ do not appear to correlate with the intensities at decametric wavelengths reported by the Harvard Radio Astronomy Station, Fort Davis, Texas, or the High Altitude Observatory, Boulder, Colorado. In those cases, however, where the Boulder data indicate that
AN EXAMPLE OF a CONTINUUM EVENT SHOWING STRUCTURE

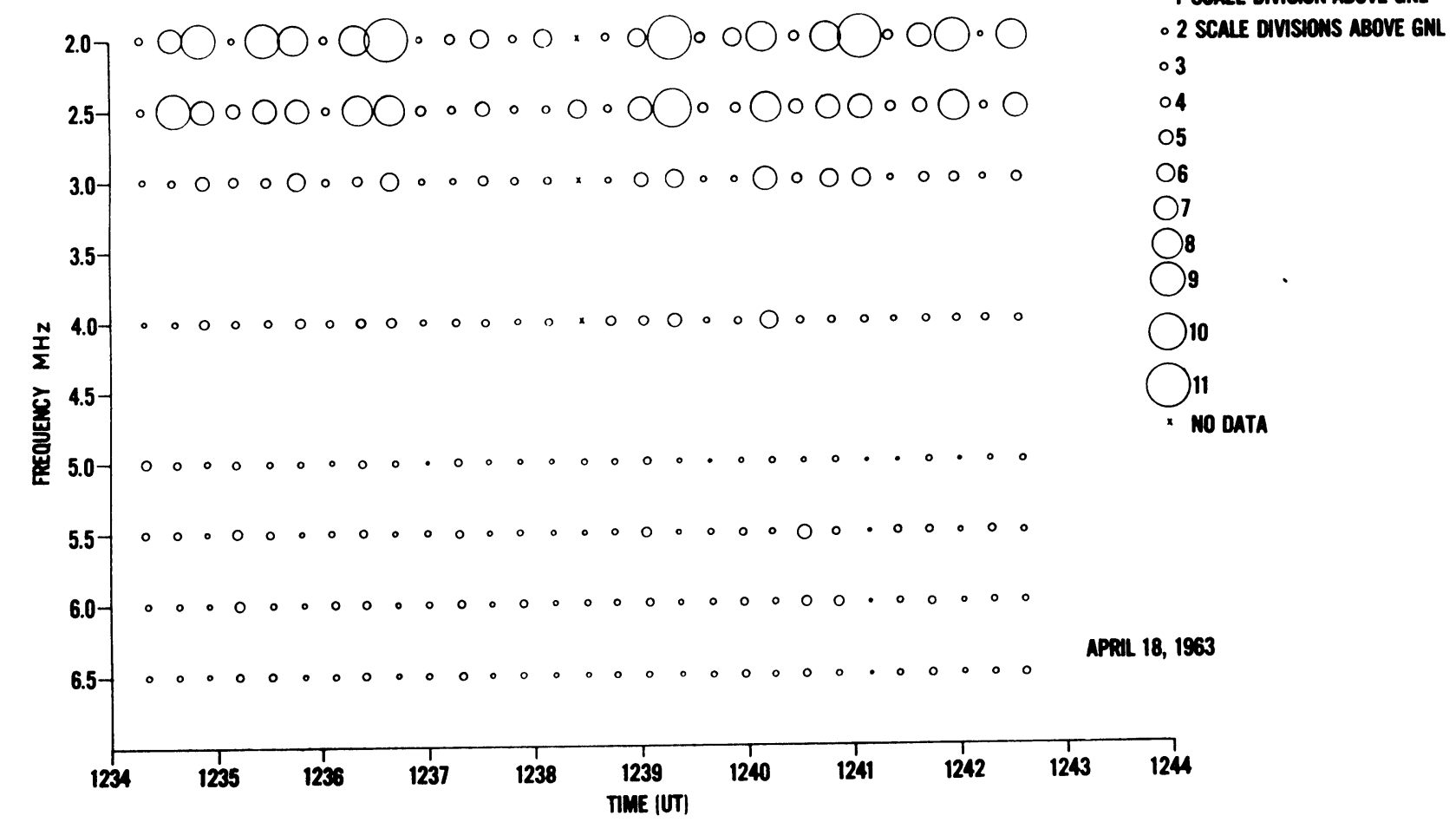

Fia. 4. - Frequency-time diagram of a solar noise storm (High Altitude Observatory data indicate a continuum event at decametric wavelengths on this occasion) showing both satellite spin modulation and intensity structure. 


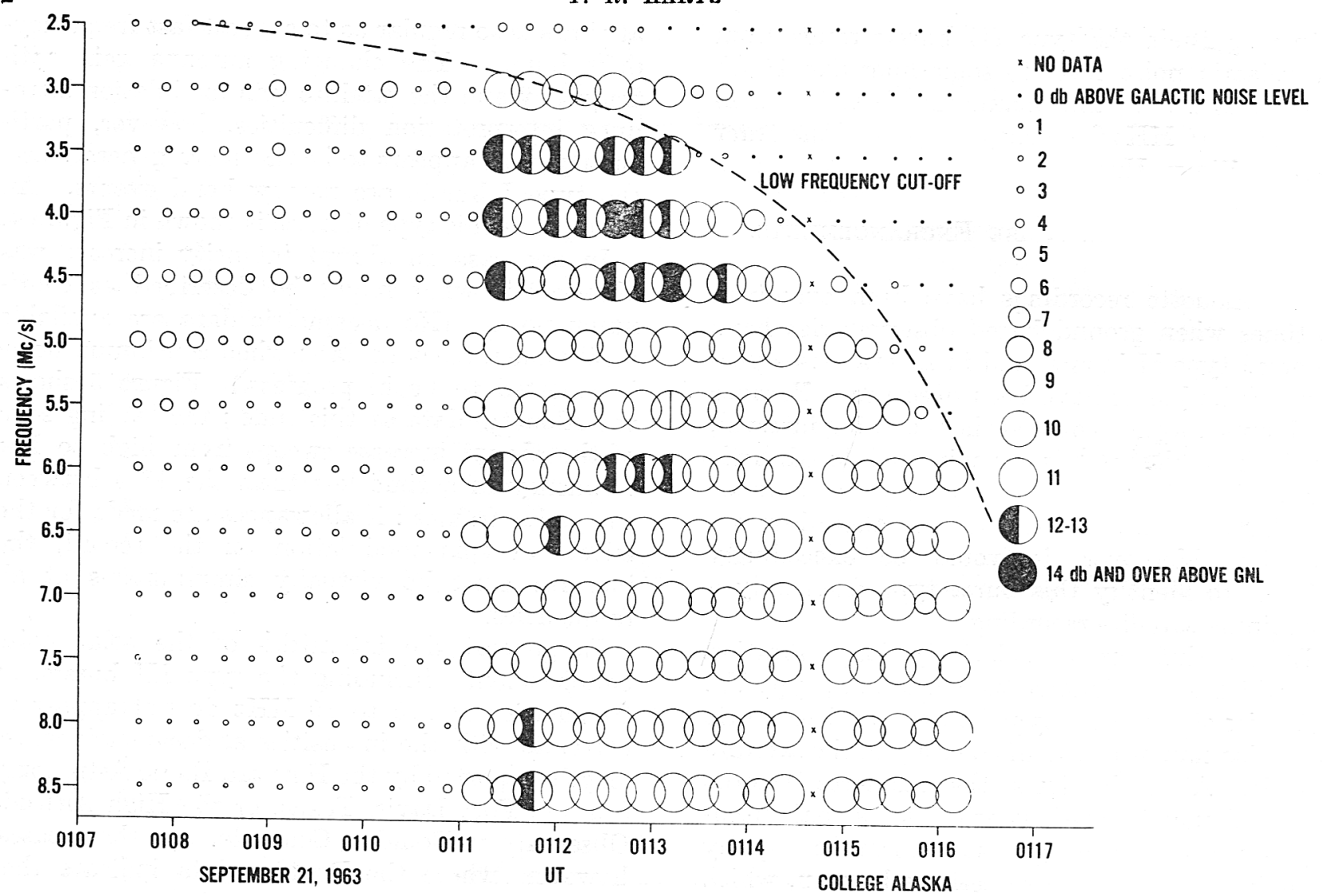

Fia. 5. - An unusual solar noise event on September 21, 1963. An abrupt order of magnitude increase occurred in the level or the continuum noise which was almost simultaneous at all frequencies. The dashed line indicates the low frequency cut off due to the antenna aperture, and the few data points below this frequency limit are produced by a known peculiarity of the receiver.

solar emissions are observable below $20 \mathrm{MHz}$, irrespective of intensity, solar noise is seen in the Alouette records down to the lowest frequencies (provided the satellite was operating), Conversely solar noise usually is not observable in the Alouette records when the Boulder data do not extend down to $20 \mathrm{MHz}$.

Finally, it should be noted that the solar emissions can provide a convenient means of measu- ring the effective aperture of a satellite antenna, and the effects of ionospheric refraction in shaping the gain pattern. Such measurements have been made using the long enduring noise enhancements seen by Alouette, and have been shown to agree well with the theoretical expectations (HARTz and ROGER, 1964).

\section{Manuscrit reçu le 30 août.}

\section{REFEREN(,ES}

Allen C. W., 1947, Mon. Not. Roy. Ast. Soc., 107, 426. Allen C. W., 1963, The Solar Corona (ed. J. W. Evans), New York, Academic Press, 1.

Boischot A., Lee R. H. and WARWICK J. W., 1960, Astrophys. J., 131, 61.

Hartz T. R., 1964, Nature, 203, 173.

HaRtz T. R., 1965, Ann. d'Astro., 27, 823.

Hartz T. R. and Roger R. S., 1964, Can. J. Phys. (in press).

VAN DE HULST H. C., 1950, Bull. Astron. Insts. Netherl., 11, 135.

Kondo M. R., 1964, Solar Radio Astronomy, Univer- sity of Michigan, Radio Astronomy Observatory Report No. 64-4, 442.

Newrirk G., 1959, Paris Symposium on Radio Astronomy (ed. R. N. Bracewell), Stanford, Stanford University Press, 149.

Shain C. A. and Higgins C. S., 1959, Austral. J. Phys., $12,357$.

WARWICK J. W., 1964 (private communication).

Westrold K. C., 1949, Austral. J. Sci. Res. A, 2, 169.

Wild J. P., Sheridan K. V. and Neylan A. A., 1959 Austral. J. Phys., 12, 369. 